pairs of cases with intervals less than 300 days and $4 \mathrm{~km}$. Other investigators have drawn conclusions based on personal observations rather than on the results of any statistical tests. For example, Heath and Hasterlick (1963) reported eight cases of leukaemia among children living in Niles, Illinois, between 1957 and 1960. This was at a time when the population was expanding sharply (in 1950 the population was about 3,500 and in 1960 about 20,000). Wood (1960), describing leukaemia in Cornwall over a 12-year period, stated that there was a tendency to find tiny foci of victims living in close proximity but there was no significant predominance in any particular district. Dowsett (1966) reported similarly of cases in Kingston, Surrey. Heath and Manning (1964) described 14 cases in four communities in the United States.

The statistical test put forward by David and Barton (1966) has the advantage that it picks out non-randomness without the need for defining a "close" distance. The criterion is based on the overall average of all possible distances between all cases. A definition of shortness in time must be made. This test was carried out (Barton et al., 1965) on cases of acute leukaemia in Northumberland and Durham, Liverpool, Birmingham, Bristol, Sheffield, and Cornwall. The results gave no evidence for the presence of clustering. Both this test and Knox's test were used by Pike et al. (1967) in analysing the incidence of Burkitt's tumour in the West Nile district of Uganda; both tests demonstrated significant space-time clustering.

In an investigation in Connecticut, Ederer et al. (1964, 1965), using a different statistical technique, analysed over 300 cases of leukaemia in children between 1945 and 1959 and found no evidence of " calendar-year clustering within towns," though, using their statistical technique, they did find evidence for clustering of poliomyelitis and hepatitis.

The 115 cases studied in Lewisham included several different clinical types of leukaemia (cytological and clinical), and the numbers of any one type were small. The data indicate that there is no evidence of clustering of leukaemia taken as a whole, nor do they provide evidence of clustering of one or other specific subtypes of leukaemia. It would appear that if cases of leukaemia are clustered at all the degrees of clustering must be very slight, and quite unlike that found in poliomyelitis and infectious hepatitis.

\section{Summary}

Two statistical criteria for testing the association of cases of leukaemia in place and time were calculated for 115 patients in the London borough of Lewisham between 1957 and 1963. The analysis gives no evidence for any clustering of these cases.

We wish to acknowledge with thanks the help given by many doctors and medical records officers in hospitals in South-east London and elsewhere. Mr. P. M. Payne, Director of the South Metropolitan Cancer Registry, kindly gave us details of his registered cases of leukaemia in the district.

The calculations were carried out on the I.C.T. Atlas Computer at the University of London Institute of Computer Science. We wish to acknowledge gratefully the expert assistance given us by Mrs. Pat Hills, Miss Norma Pateman, and Miss Pat Williamott, of University College, London, in processing these data. Dr. Malcolm Pike, of the M.R.C. Statistical Research Unit at University College Hospital Medical School, London, kindly helped us concerning the calculations with the Knox test.

REFERENCES

Ager, E. A., Schuman, L. M., Wallace, H. M., Rosenfield, A. B., and Gullen, W. H. (1965). F. chron. Dis., 18, 113.

Barton, D. E., David, F. N., and Merrington, M. (1965). Ann. hum. Genet., 29, 97.

Clemmesen, J., Busk, T., and Nielsen, A. (1952). Acta radiol. Diagn., 37, 223.

David. F. N., and Barton, D. E. (1966). Brit. 7. prev. soc. Med., 20, 44. Dowsett, E. G. (1966). Brit. $\not$. Cancer, 20, 16 .

Ederer, F., Myers, M. H., Eisenberg, H., and Campbell, P. C. (1965). f. nat. Cancer Inst., 35, 625.

Heath C. W., and Hasterlick, R. J. (1963). Amer. F. Med., 34, 796.

Heath C. W., and Hasterlick, R. J. (1963). Amer. 7 .

$\overline{\text { Kellett, C. E. (1937). Arch. Dis. Childh., 12, } 239 .}$

Kellett, C. E. (1937). Arch. Dis. Childh., 12, 239.

Lundin, F. E., Fraumeni, J. F., Lloyd, J. W., and Smith, E. M. (1966), 7. nat. Cancer Inst., 37, 123.

Mainwaring, D. (1966).' Brit. F. prev. soc. Med., 20, 189.

Meighan, S. S., and Knox, E. G. (1965), Cancer (Philad.), 18, 811.

Pike, M. C., Williams, E. H. and Wright B. (1967). Brit. med. F., 2,

Wood, E. E. (1960). Ibid., 1, 1760.

\title{
Transit Times of Food in Patients with Diverticulosis or Irritable Colon Syndrome and Normal Subjects
}

\author{
O. N. MANOUSOS,* M.B., D.PHIL.; S. C. TRUELOVE,* M.D., F.R.C.P. ; K. LUMSDEN, † M.B., B.CHIR., D.M.R.E.
}

Brit. med. F., 1967, 3, 760-762

The rate of passage of food residue through the alimentary canal of normal human subjects has been studied extensively, but there are no relevant data with regard to patients with diverticula of the colon.

Hurst (Hertz) (1907) administered bismuth carbonate mixed with food to normal subjects and followed the progress of the food residue by means of radiographs; he found that a proportion of the radio-opaque material was still in the large bowel three days after its administration. Alvarez and Freedlander (1924) studied the transit times by means of small glass beads taken with food and found that only $70 \%$ of the beads had been passed by the third day. Similar results were obtained by Burnett (1923), who used millet seeds as the tracer substance. Todd (1930) and Lönnerblad (1951) studied the transit time

\footnotetext{
* Nuffield Department of Clinical Medicine, the Radcliffe Infirmary, Oxford.

† Consuitant Radiologist. United Oxford Hospitals, Oxford.
}

of the small intestine by using barium sulphate mixed with water, but, as Cole (1914) suggested, unless the tracer substance is mixed with an ordinary meal the results are not representative of the actual progress of food residues through the gastrointestinal canal.

The figures of transit times given by Hurst (1919) for the normal are generally accepted (Barclay, 1933 ; Feldman, 1948). The food reaches the caecum in three to four hours, the hepatic flexure in six hours, the splenic flexure in 10 hours; between 18 and 24 hours the sigmoid is filled and some of the contents have been expelled; but, as was pointed out by Hurst himself, there is a wide variation in the normal transit. Indigestible material (roughage) increases the speed of food residue through the digestive tract, as has been shown by the comparative studies of McCance et al. (1953). They studied radiologically the transit time of white and brown bread administered with a small amount of barium sulphate to normal subjects. It was 
found that the residue from the brown bread left the colon 24 hours sooner than that from the white bread.

\section{Present Study}

The transit time of food through the digestive tract was studied in 43 patients with diverticulosis (20 males and 23 females; mean age 68 years), 75 patients with the irritable colon syndrome (40 males and 35 females; mean age 42 years), and 88 normal subjects (42 males and 46 females; mean age 59 years).

A minority of the patients with diverticulosis and some of the patients with the irritable colon syndrome were on treatment with anticholinergic drugs because of chronic intermittent symptoms; the medication in these patients was stopped at least two days before the period of observation started.

Methods.-The subjects studied were instructed to drink $30 \mathrm{ml}$. of a preparation of barium sulphate (Fotogel or Micropaque) with each of their four main meals in one day. The next morning a radiograph of the abdomen was taken, and this was repeated on each successive morning (up to a maximum of six) until the radio-opaque material had virtually disappeared. (This procedure has also been used in order to obtain information regarding the incidence of diverticulosis in the general population (Manousos et al., 1967b).) Two factors were examined: (1) the head of the barium column indicating the progress of food eaten 24 hours previously, and (2) the number of days that the barium-that is, the food-took to disappear from the gastrointestinal tract.

\section{Results}

As shown in Table $I$, the head of the barium column 24 hours after administration of barium with food was above the sigmoid colon in more than $27 \%$ of the normal subjects, whereas the proportions of patients with diverticulosis and the irritable colon syndrome were $9.3 \%$ and $5.3 \%$ respectively. Table II shows that the difference in transit of food residue between normals and patients with diverticulosis is statistically significant.

When the number of days required for the radio-opaque material to leave the colon is taken as a measure of the progress

TABLE I.-Progress of Food 24 Hours After Ingestion

\begin{tabular}{|c|c|c|c|c|c|c|c|c|c|c|}
\hline & \multicolumn{2}{|c|}{ Rectum } & \multicolumn{2}{|c|}{ Sigmoid } & \multicolumn{2}{|c|}{ Descending } & \multicolumn{2}{|c|}{$\begin{array}{c}\text { Splenic Flexure } \\
\text { or Above }\end{array}$} & \multicolumn{2}{|c|}{$\begin{array}{c}\text { Total not } \\
\text { ReachedSigmoid }\end{array}$} \\
\hline & No. & $\%$ & No. & $\%$ & No. & $\%$ & No. & $\%$ & No. & $\%$ \\
\hline $\begin{array}{l}\text { Normal } \\
\text { controls }\end{array}$ & 54 & $61 \cdot 4$ & 10 & $11 \cdot 4$ & 7 & 8.0 & 17 & $19 \cdot 3$ & 24 & $27 \cdot 3$ \\
\hline $\begin{array}{l}\text { diverticulosis } \\
\text { Patients with }\end{array}$ & 36 & $83 \cdot 7$ & 3 & $7 \cdot 0$ & 3 & $7 \cdot 0$ & 1 & $2 \cdot 3$ & 4 & $9 \cdot 3$ \\
\hline $\begin{array}{l}\text { irritable colon } \\
\text { syndrome }\end{array}$ & 68 & $90 \cdot 7$ & 3 & 4.0 & 2 & $2 \cdot 7$ & 2 & $2 \cdot 6$ & 4 & $5 \cdot 3$ \\
\hline
\end{tabular}

\begin{tabular}{c|c|c|c}
\hline & TABLE II \\
\hline & Rectum or Sigmoid & Above Sigmoid & Total \\
\hline $\begin{array}{c}\text { Normal controls } \ldots \text { Patients with diverticulosis } \\
\text { Total }\end{array}$ & 64 & 24 & $\begin{array}{c}88 \\
43\end{array}$ \\
\hline$\chi^{\prime}=5.5 . \quad \mathrm{n}=1 . \quad \mathrm{r}<0.02$. & 103 & 28 & 131 \\
\hline
\end{tabular}

TABLE III.-Number of Days Before the Food Left the Gastrointestinal Tract

\begin{tabular}{|c|c|c|c|c|c|c|c|c|c|}
\hline & \multicolumn{2}{|c|}{2} & \multicolumn{2}{|c|}{3} & \multicolumn{2}{|c|}{4} & \multicolumn{2}{|c|}{5 or More } \\
\hline & & No. & $\%$ & No. & $\%$ & No. & $\%$ & No. & $\%$ \\
\hline $\begin{array}{l}\text { Normal controls } \\
\text { Diverticulosis } \\
\text { Irritable colon }\end{array}$ & $\because$ & $\begin{array}{r}3 \\
7 \\
13\end{array}$ & $\begin{array}{r}3 \cdot 4 \\
16 \cdot 3 \\
18 \cdot 1\end{array}$ & $\begin{array}{l}29 \\
17 \\
33\end{array}$ & $\begin{array}{l}33 \cdot 0 \\
39 \cdot 5 \\
45 \cdot 8\end{array}$ & $\begin{array}{r}27 \\
9 \\
13\end{array}$ & $\begin{array}{l}30 \cdot 7 \\
20 \cdot 9 \\
18 \cdot 1\end{array}$ & $\begin{array}{l}29 \\
10 \\
13\end{array}$ & $\begin{array}{l}33 \cdot 0 \\
23 \cdot 3 \\
18 \cdot 1\end{array}$ \\
\hline
\end{tabular}

of food residue through the alimentary canal it is found that five or more days are required by $33 \%$ of the normal subjects, $23.3 \%$ of the patients with diverticulosis, and $18.1 \%$ of the patients with the irritable colon syndrome (Table III). Again the difference between normals and patients with diverticulosis is statistically significant (Table IV).

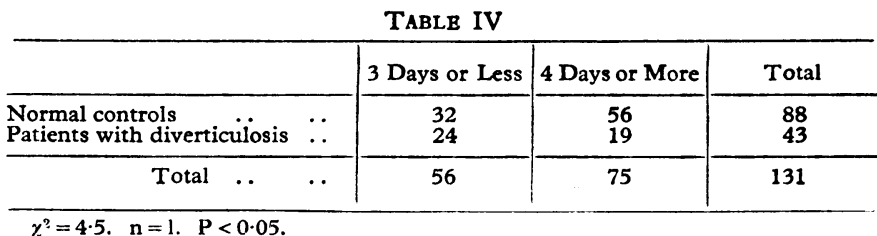

\section{Discussion}

Constipation has been thought to be a factor of aetiological significance in the development of diverticula by many investigators (Fischer, 1900 ; Beer, 1904 ; Turell, 1959 ; De La Vega et al., 1964), and according to Jordan (1926) diverticulosis is a special manifestation of chronic intestinal stasis. The term "constipation" often has a vague meaning (Johnson, 1943), but when constipation is defined as "undue delay of passage of stool and, therefore, the difficult expulsion of hard dry matter," then the incidence of constipation in diverticular disease is only $14 \%$ (Horner, 1958).

Barclay (1933) pointed out that the statements of patients about constipation are often proved to be unreliable when they are examined radiologically.

The present study of the transit times shows that intestinal stasis is noi present in patients with diverticulosis. On the contrary the progress of food through the gastrointestinal canal is significantly faster in patients with diverticulosis than in normal controls.

The similarity of the pattern of transit times between patients with diverticulosis and those with the irritable colon syndrome is of interest. The chronic intermittent symptoms of the two conditions are identical, and Bockus (1964), who made repeated radiological examinations in patients with the irritable colon syndrome, found that a proportion of them develop diverticula some years after the diagnosis of irritable colon, and pointed out that colonic irritability may be a predisposing factor in the development of diverticula.

Pathological studies (Keith, 1910 ; Edwards, 1939 ; Morson, 1963 ; Williams, 1963) suggest that diverticulosis may be the result of incoordinated activity of the colonic musculature. The function of the colon in patients with diverticulosis has not been studied extensively. Painter and Truelove (1964) found that injection of morphine produced high pressures inside segments of the colon bearing diverticula. They suggested that in diverticulosis the colon may show exaggerated responses to normal stimuli-for example, food or drink. The effect of eating a meal on the motility of the sigmoid colon of patients with diverticulosis has been studied (Manousos et al., 1967a). The results indicate that the effect is greater than that observed in normal subjects, and, again, a similarity was observed between the response of the colon in patients with diverticula and patients with the irritable colon.

As shown by the study of the transit times and the review of the literature, there are many points in common between colonic diverticulosis and the disorders of colonic motor activity covered by the term "irritable colon syndrome." It appears likely that in both conditions the underlying mechanism is a functicnal disorder of the colonic musculature. The fact that many cases of colonic diverticulosis are quite symptomless seems to contradict this idea, unless we accept the view put forward by Williams (1963) that incoordinated muscular activity of the colon may be present without causing any symptoms. 


\section{Summary}

The transit times of food residues through the gastrointestinal tract have been studied by administering food mixed with a small amount of barium sulphate. Observations were made on 88 normal subjects, 75 patients with the irritable colon syndrome, and 43 patients with diverticulosis. The transit times were found to be substantially shorter in the patients with diverticula than in normal subjects and to follow closely the transit shown by patients with the irritable colon syndrome. This finding is put forward as evidence supporting the hypothesis that incoordinated colonic activity is the basic abnormality in diverticulosis.

We wish to express our gratitude to all the patients and normal subjects who volunteered to take part in this study, the radiographers of the United Oxford Hospitals for their help, and the Medical Research Council for financial support.

REFERENCES

Alvarez, W. C., and Freedlander, B. L. (1924). F. Amer. med. Ass., $83,576$.

Barclay, A. E. (1933). The Digestive Tract, p. 279. London.

Beer, E. (1904). Amer. ₹. med. Sci., 128, 135.
Burnett, F. L. (1923). Amer. F. Roentgenol., 10, 599.

Cole, L. G. (1914). Amer. f. med. Sci., 148, 92.

Edwards, H. C. (1939). Diverticula and Diverticulitis of the Intestine, p. 195. Bristol.

Feldman, M. (1948). Clinical Roentgenology of the Digestive Tract, 3rd ed., p. 473. London.

Fischer, M.' H. (1900). भ. exp. Med., 5, 333

Horner, J. L. (1958). Amer. $\not$. dig. Dis., 3, 343

Hurst (Hertz), A. F. (1907). Guy's Hos?. Rep., 61, 389.

Hurst, A. F. (1919). Constipation and Allied Intestinal Disorders, 2nd ed. London.

Johnson, T. A. (1943). In H. L. Bockus's Gastroenterology, vol. 2, p. 683. Philadelphia.

Jordan, A. C. (1926). Chronc Intestinal Stasis, 2nd ed. London.

Keith, A. (1910). Brit. med. $¥$., 1, 376.

Lönnerblad, L. (1951). Acta radiol. (Stockh.), Suppl. No. 88.

McCance R. A., Prior, K. M., and Widdowson, E. M. (1953). Brit. F. Nutr., 7, 98 .

Manousos, O. N., Ritchie, J., and Truelove, S. C. (1967a). To be published.

published. S. C., and Lumsden, K. (1967b). Brit. med. F., 3, 762 .

Morson, B. C. (1963). Brit. F. Radiol., 36, 385.

Painter, N. S., and iruelove, S. C. (1964). Gut, 5, 201.

Todd, T. W. (1930). The Beaumont Foundation Lectures, series No. 9 , p. 79. Bal'incre.

Turell, R. (1959). Diseases of the Colon and Anorectum, vol. 2, p. 633. London.

Vega, de la, J. M., Gonzalez, J. N., and Ponce de Leon, A. (1964). In H. L. Bockus's Gastroenterology, 2nd ed., vol. 2, p. 933 . Philadelphia.

Williams, I. (1963). Brit. 7. Radiol., 36, 393.

\title{
Prevalence of Colonic Diverticulosis in General Population of Oxford Area
}

\author{
O. N. MANOUSOS,* M.B., D.PHIL. ; S. C. TRUELOVE,* M.D., F.R.C.P. ; K. LUMSDEN, $†$ M.B., B.CHIR., D.M.R.E.
}

Brit. med. F., 1967, 3, 762-763

It has been generally accepted that diverticulosis of the colon is a common condition in Western countries, especially in the older age groups (Barborka, 1958; Reichman and Watkins, 1962). However, up to the present time the frequincy of diverticulosis has been calculated from radiological studies carried out on patients or from post-mortem examinations in hospital, and consequently the results apply only to selected sections of the population. Spriggs and Marxer (1925) examined 1,000 consecutive barium enemas and found diverticula in $10 \%$. Rankin and Brown (1930) studied 24,620 barium enemas and found diverticula in $5.7 \%$. They reported a similar prevalence of diverticulosis (5.2\%) in 1,925 necropsies. All except one of the necropsies were carried out on subjects older than 40 years.

Pemberton et al. (1947) reviewed a large number of radiographs of the colon and found diverticula in $8.5 \%$. Welch et al. (1953) examined 2,000 barium enemas and found diverticula in $20 \%$ of the patients over the age of 60 .

Until some years ago diverticula were more common in men than in women (Spriggs and Marxer, 1925; Ochsner and Bargen, 1935); recently, however, it appears that a change in sex ratio is taking place and a female preponderance is now commonly observed (Ford, 1953 ; Brown and Toomey, 1960). Table I shows the sex ratio in diverticulosis and diverticulitis reported by various authors. In a recent study on the prognosis of diverticulosis and diverticulitis (Manousos and Truelove, 1967) it was found that whereas below the age of 60 diverticula were equally common in men and women, above that age the condition was much more common in women. It was also shown that the number of patients admitted to hospital with diverticulosis, diverticulitis, and the complications of diverti-

\footnotetext{
* Nuffield Department of Clinical Medicine, the Radcliffe Infirmary, Oxford.

t Consultant Radiologist, United Oxford Hospitals, Oxford.
}

cular disease is increasing, and this probably indicates a true increase in the prevalence of the disease as a whole.

In view of the lack of accurate information on the frequency of diverticulosis in the population at large the present study was made.

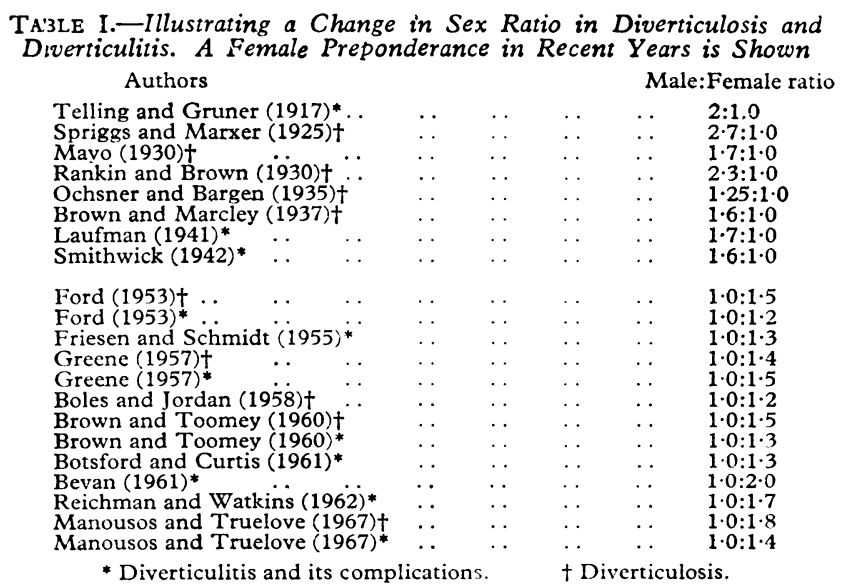

\section{Methods and Subjects}

The radiological appearances of the colon of 109 subjects without gastrointestinal symptoms were studied. The majority of the subjects were healthv volunteers who were either members of the staff of the Radcliffe Infirmary or visitors to inpatients. A minority of the subjects were patients in a geriatric unit (Cowley Road Hospital, Oxford) who were volunteers and who were completely free from gastrointestinal symptoms. 